\title{
Sildenafil (Viagra) for male erectile dysfunction: a meta-analysis of clinical trial reports RA Moore*2, JE Edwards ${ }^{1}$ and HJ McQuay ${ }^{1}$
}

Address: ${ }^{1}$ Pain Research and Nuffield Department of Anaesthetics, University of Oxford, Oxford Radcliffe Hospital, The Churchill, Headington, Oxford OX3 7LJ, UK and 2Pain Research and Nuffield Department of Anaesthetics, University of Oxford, The Churchill, Headington, Oxford, OX3 $7 \mathrm{LJ}$

E-mail: RA Moore* - andrew.moore@pru.ox.ac.uk; JE Edwards - jayne.edwards@pru.ox.ac.uk; HJ McQuay - henry.mcquay@pru.ox.ac.uk ${ }^{*}$ Corresponding author

This article is available from: http://www.biomedcentral.com/147I-2490/2/6

(C) 2002 Moore et al; licensee BioMed Central Ltd. Verbatim copying and redistribution of this article are permitted in any medium for any purpose, provided this notice is preserved along with the article's original URL.

\begin{abstract}
Background: Evaluation of company clinical trial reports could provide information for metaanalysis at the commercial introduction of a new technology.

Methods: Clinical trial reports of sildenafil for erectile dysfunction from September 1997 were used for meta-analysis of randomised trials (at least four weeks duration) and using fixed or dose optimisation regimens. The main outcome sought was an erection, sufficiently rigid for penetration, followed by successful intercourse, and conducted at home.

Results: Ten randomised controlled trials fulfilled the inclusion criteria (2/23 men given sildenafil and II3I placebo). NNT or NNH were calculated for important efficacy, adverse event and discontinuation outcomes. Dose optimisation led to at least $60 \%$ of attempts at sexual intercourse being successful in $49 \%$ of men, compared with II\% with placebo; the NNT was 2.7 (95\% confidence interval 2.3 to 3.3). For global improvement in erections the NNT was I.7 (I.6 to I.9). Treatment-related adverse events occurred in $30 \%$ of men on dose optimised sildenafil compared with II\% on placebo; the NNH was 5.4 (4.3 to 7.3). All cause discontinuations were less frequent with sildenafil $(10 \%)$ than with placebo $(20 \%)$. Sildenafil dose optimisation gave efficacy equivalent to the highest fixed doses, and adverse events equivalent to the lowest fixed doses.

Conclusion: This review of clinical trial reports available at the time of licensing agreed with later reviews that had many more trials and patients. Making reports submitted for marketing approval available publicly would provide better information when it was most needed, and would improve evidence-based introduction of new technologies.
\end{abstract}

\section{Background}

Meta-analyses that include otherwise unpublished randomised trials are uncommon [1], but are welcome, and can inform in circumstances where information is contradictory. The example of tramadol in acute pain, where information on 3,500 patients was made available, explained the results of two studies, one showing that tramadol was a highly efficacious analgesic [2], the other showing it to be no different from placebo [3]. The truth was somewhere between. Despite the fact that tramadol had been in common use in some European countries for many years, fulfilling regulatory requirements for the 
United States required studies to be conducted to contemporary requirements, and meta-analysis brought useful results to light.

Meta-analysis of randomised studies before a new technology has become commercially available is even more rare, though there is at least two examples $[4,5]$. Metaanalyses are usually performed some years after first commercial availability because the publication of randomised trials performed for efficacy and/or safety reasons takes time. The importance of meta-analysis in drug development and regulatory procedures is increasingly recognised $[5,6]$.

The results of meta-analysis are undoubtedly important, both in the regulatory process and for evaluation of rare but serious adverse events. For COX-2 inhibitors metaanalysis was being planned before the randomised trials in order to examine the relationship between treatments and rare events $[5,6]$.

The point of greatest change, though, is in the period immediately after commercial introduction. Media interest can raise patient expectations at a time where healthcare professionals and organisations have least knowledge and experience, and when few have had the opportunity to consider the full implications of the new technology on budgets and services. For sildenafil, for instance, $85 \%$ of first time prescriptions occurred in the first 12 weeks of availability in one New England healthcare provider [7]. It is at this point, the point of marketing approval, when there is the greatest need for the best information. At best only a small number of trials may have been published, and though they can be large, and usually are powered to detect a difference from placebo or common current practice, they are unlikely to be able to measure accurately the size of the benefit.

We sought to assess whether clinical trial reports presented for marketing approval would provide the basis for a systematic review at the time of launch if they were publicly available. We did this with reference to the erectile dysfunction treatment sildenafil (Viagra), using clinical trial reports made available by Pfizer Ltd.

\section{Methods}

No search strategy was required because this review was of material made available by Pfizer UK Ltd in the form of clinical trial reports used in a marketing authorisation application for sildenafil (Viagra) in September 1997. QUORUM guidelines were otherwise followed [7]. The prior intention was to use studies that were relevant to the use of sildenafil in clinical practice. This required the setting to be the home, not the clinic, use of sildenafil as required, rather than fixed dosing schedules (such as daily tablets), and studies of a minimum duration, which we set arbitrarily as four weeks.

Excluded were studies with laboratory measures of penile tumescence or rigidity with single doses of sildenafil, studies that only investigated erectile function in a clinic setting, studies that used fixed daily dosing rather than as required, and studies that were shorter than four weeks. Included were randomised trials that investigated sildenafil, with efficacy or safety data, were longer than four weeks, conducted in the home setting, and with doses in the licensed range of $25 \mathrm{mg}$ to $100 \mathrm{mg}$ as required, although lower and higher doses would be analysed if there were sufficient information. Clinical trials in men with erectile dysfunction caused specifically by single causes like spinal cord trauma or diabetes were not included because, taken with the other data, they would constitute clinical heterogeneity.

Each report was scored for quality using a three item, 1-5 score, quality scale [8]. Points were awarded to studies according to whether they were randomised and double blind and mentioned withdrawals or drop-outs from the study. An additional point was awarded if the method of randomisation or double blinding was described and was appropriate.

From each trial we extracted the number of patients treated per group, dosing regimen, study design, and the number of patients with efficacy and/or safety outcomes. The denominator was the number of patients randomised so that results were on an intention-to-treat basis. This analysis includes all randomised patients regardless of the completion of diaries, protocol concordance or missing data. Patients with missing or illegible diary data were assumed to have $0 \%$ intercourse success rate. In addition, this analysis included sexual intercourse attempts that were unsuccessful for reasons not attributable to sildenafil i.e. factors other than the erection being insufficiently hard or long-lasting. RAM extracted the data into tables, and these were then read and checked by other authors.

For the review, a prior definition of efficacy was a man with a consistent three-part outcome, consisting of an erection, sufficiently rigid for penetration, and followed by successful intercourse. Other efficacy outcomes of interest were the number of men with the highest two responses on the International Index of Erectile Function (IIEF) questions 3 and 4, and global evaluations of treatment efficacy by patients [9]. The number of grade 3 or 4 erections (at least hard enough for penetration) and successful erections were also noted.

Adverse events were also sought. These were the number of men with any treatment-related adverse event, the total 
number of men discontinuing, those discontinuing through lack of efficacy or through adverse events, adverse events rated severe or serious, and information on particular adverse events.

\section{Outcomes actually available and chosen were Efficacy}

- Number of men in whom the proportion of successful attempts at sexual intercourse was more than $60 \%$

- Number of men in whom the proportion of successful attempts at sexual intercourse was more than $40 \%$

- Number of men reporting that their erections had been improved on a global question (global A; "Has the treatment you have been taking over the past four weeks improved your erections?").

\section{Erections}

- The weighted mean number of weekly erections was calculated.

- The weighted mean success rate was calculated.

- The weighted mean weekly number of successful occasions where intercourse occurred was calculated from these numbers.

\section{Adverse events}

- Treatment-related adverse events

- Severe adverse events

- Serious adverse events

- Dyspepsia

- Headache

- Vasodilation (flushing)

Discontinuations

- All-cause discontinuations

- Discontinuations due to inefficacy

- Discontinuations due to adverse events

A prior intention was to analyse effectiveness and harm according to dose. Dosing could be fixed, or could be optimised where patients took an initial dose of $50 \mathrm{mg}$, and then move up to $100 \mathrm{mg}$ or down to $25 \mathrm{mg}$ on subsequent occasions depending on their individual judgement of the efficacy or adverse events caused by that dose.
There was no intention of pooling mean data because the results were not known to have a normal distribution [10], but rather to find dichotomous data. Relative benefit and relative risk estimates were calculated with $95 \%$ confidence intervals using a fixed effects model [11]. No pooling was done unless there were at least two studies or at least 200 men in the comparison. The number needed to treat (NNT) and number needed to harm (NNH), with confidence intervals, were calculated by the method of Cook and Sackett [12]. Confidence intervals (95\%) for single samples were calculated for proportions [13]. Heterogeneity tests were not used as they have previously been shown to be unhelpful [13]. Clinical criteria for homogeneity was defined before analysis and examined graphically [14]. Publication bias was not assessed using funnel plots as these tests have been shown to be unhelpful $[15,16]$, and publication bias was not an issue here.

Relative benefit or risk was considered to be statistically significant when the $95 \%$ confidence interval did not include 1. NNT or NNH values were only calculated when the relative risk or benefit was statistically significant, and are reported with the 95\% confidence interval. Statistical significance of any difference between numbers needed to treat for different doses was assumed if there was no overlap of the confidence intervals, and additionally tested using the $\mathrm{z}$ statistic [16]. Calculations were performed using Microsoft Excel 98 on a Power Macintosh G4.

\section{Results}

Twenty-seven clinical trial reports were made available, all prepared for a marketing authorisation application, and dated September 1997. Some of these were single dose use in laboratory setting with penile plethysmography as an outcome. Others were open extensions of randomised studies. These were not useful, and 17 were excluded; details of excluded studies and reasons for exclusions are given in Additional File 1. There were no details of any ongoing studies.

Ten studies could be included (study report numbers 101, 102, 103, 106, 355, 356, 359, 361, 363, 364) with 1846 men given sildenafil ( 25 to $100 \mathrm{mg}$ ) and 1131 given placebo. An additional 277 men were given sildenafil at $5 \mathrm{mg}$ or $200 \mathrm{mg}$. Details of trial design for the included studies is given in Additional File 2. Nine were parallel group and one had a crossover design, with fixed doses of sildenafil, or dose-optimised sildenafil, or both, and all had a placebo comparator group. Study duration was a minimum of six weeks and a maximum of six months.

\section{Description of included studies}

The number or percentage of men with various efficacy (more than $60 \%$ or $40 \%$ success, global rating, number erections and successful attempts at intercourse)(includ- 
ing treatment related adverse events and discontinuations) and adverse event outcomes are shown for individual trials in Additional File 3. These outcomes were taken at 12 weeks, or at a time as close to 12 weeks as possible.

All ten of the included clinical trial reports had a quality score of 3 (two) or 4 (eight) out of 5 . All were randomised but only two stated how randomisation was achieved. All stated that they were double blind, and six explained how blinding was achieved (double-dummy, identical placebo). All studies described withdrawals clearly and were performed on an intention-to-treat basis incorporating patients with unsuccessful attempts for reasons not associated with sildenafil.

For inclusion in a study a man typically had to have a minimum six-month history of erectile dysfunction, be 18 years or older, be in a heterosexual relationship for at least six months and be able to give written consent. There was typically a long (21 point) list of exclusions that included anatomical deformities, other sexual disorders, diabetes with poor control and/or untreated proliferative retinopathy, recent (six month) history of heart attack or stroke, significant cardiovascular disease, active peptic ulceration or bleeding, use of other treatments for erectile dysfunction and known history of retinitis pigmentosa. All of the clinical exclusions were sensible and would form part of clinical advice regarding advisability of any new treatment. Nine of the ten studies described men as having erectile dysfunction of organic, mixed and psychogenic aetiology; a small number of men in the trials also had diabetes.

Typically men would attend for a screening visit to record medical information and to have a physical examination. Treatments were to be taken as required before anticipated sexual activity on an outpatient basis over periods up to 12 weeks. No more than one treatment was to be taken on any one day.

Efficacy was determined using the 15 questions of the IIEF questionnaire, plus a global efficacy assessment ("Has the treatment you have been taking over the past four weeks improved your erections?"), plus a log or erectile function recording details of erections, their hardness, its duration, and whether or not erection was maintained long enough to complete the sexual activity. The main reported outcomes were responses to IIEF questions 3 ("Over the past four weeks, when you attempted sexual intercourse, how often were you able to penetrate your partner?") and question 4 ("Over the past four weeks, during sexual intercourse, how often were you able to maintain your erection after you had penetrated your partner?").
Adverse events, observed or volunteered, were recorded, and investigators were to pursue all adverse events. Serious adverse events were defined as fatal, life-threatening, permanently disabling, requiring hospital admission, congenital abnormality, cancer or overdose, or considered serious enough for immediate reporting.

\section{Results Of meta-analysis Efficacy}

The efficacy results closest to the prior definition of efficacy of a man with the consistent three part outcome, consisting of an erection, sufficiently rigid for penetration, and followed by successful intercourse were the number of men in whom at least $60 \%$ or at least $40 \%$ of attempts at sexual intercourse were successful. The results for at least $60 \%$ of attempts successful are shown in Table 1 and Figure 1 . All doses were significantly better than placebo. In three studies $48 \%$ of men had this outcome with dose optimisation compared with $11 \%$ with placebo; the number needed to treat was 2.7 (95\% CI 2.3 to 3.2). Dose-optimisation produced a significantly lower (better) NNT than a $25 \mathrm{mg}$ fixed dose.

\section{Men with at least $60 \%$ success}

\section{Percent with sildenafil}

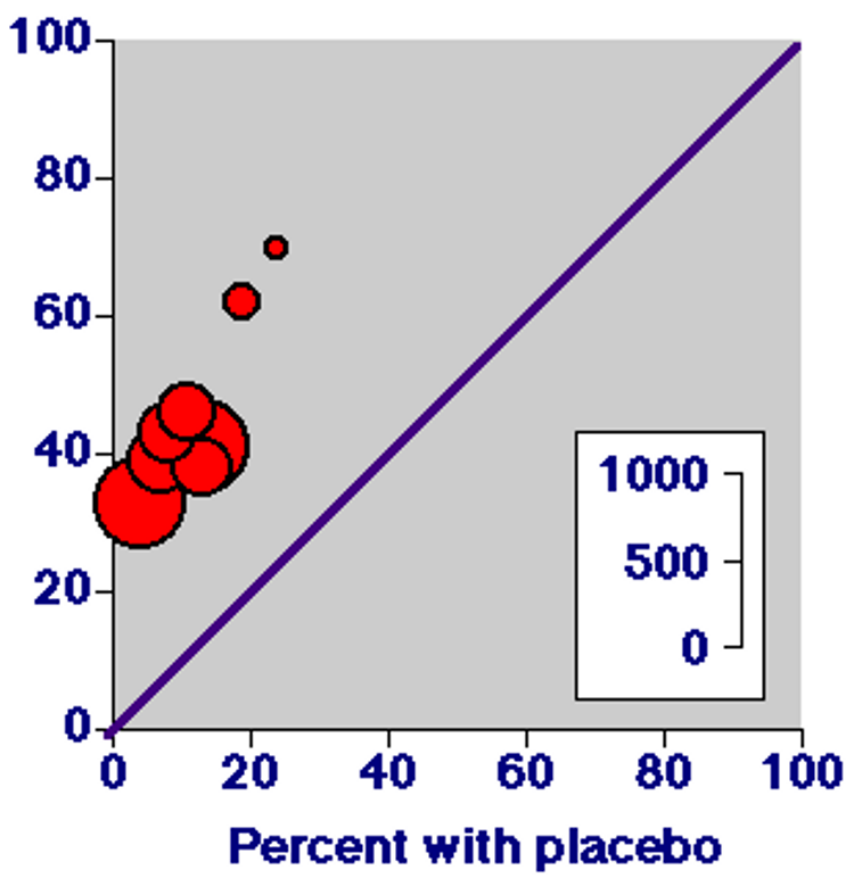

Figure I

Each symbol represents the percentage of men with at least $60 \%$ success with viagra or placebo. Size of the symbol is proportional to the size of the study 
Table I: At least $60 \%$ of attempts at sexual intercourse successful

\begin{tabular}{|c|c|c|c|c|c|}
\hline \multirow[b]{2}{*}{ Dosing (mg) } & \multirow[b]{2}{*}{ Number of trials } & \multicolumn{3}{|c|}{ Number (\%) with outcome } & \multirow[b]{2}{*}{ NNT $(95 \% \mathrm{Cl})$} \\
\hline & & Sildenafil & Placebo & $\begin{array}{l}\text { Relative benefit } \\
\quad(95 \% \mathrm{Cl})\end{array}$ & \\
\hline 25 & 3 & $88 / 3 / 2(28)$ & $43 / 426(10)$ & $3.0(2.1$ to 4.2$)$ & 5.5 (4.2 to 8.1$)$ \\
\hline 50 & 5 & $216 / 511(42)$ & $62 / 607(10)$ & 4.3 (3.3 to 5.6$)$ & 3.1 (2.7 to 3.7$)$ \\
\hline 100 & 5 & $223 / 506(44)$ & $62 / 607(10)$ & $4.4(3.4$ to 5.8$)$ & $3.0(2.6$ to 3.5$)$ \\
\hline 200 & 2 & $93 / 191(49)$ & $19 / 181(10)$ & $4.5(2.9$ to 7.1$)$ & $2.6(2.2$ to 3.4$)$ \\
\hline Dose optimised & 3 & $183 / 379(48)$ & $43 / 376(11)$ & $4.2(3.1$ to 5.6$)$ & $2.7(2.3$ to 3.2$)$ \\
\hline
\end{tabular}

Table 2: At least $40 \%$ of attempts at sexual intercourse successful

\begin{tabular}{|c|c|c|c|c|c|}
\hline \multirow[b]{2}{*}{ Dosing (mg) } & \multirow[b]{2}{*}{ Number of trials } & \multicolumn{3}{|c|}{ Number (\%) with outcome } & \multirow[b]{2}{*}{ NNT $(95 \% \mathrm{Cl})$} \\
\hline & & Sildenafil & Placebo & $\begin{array}{c}\text { Relative benefit } \\
(95 \% \mathrm{Cl})\end{array}$ & \\
\hline 25 & 3 & $122 / 312(39)$ & $70 / 426(16)$ & $2.6(2.0$ to 3.3$)$ & $4.4(3.4$ to 6.2$)$ \\
\hline 50 & 5 & $269 / 5 I I(53)$ & $102 / 607$ (17) & $3.3(2.7$ to 4.0$)$ & $2.8(2.4$ to 3.3$)$ \\
\hline 100 & 5 & $272 / 506(54)$ & $102 / 607$ (17) & $3.3(2.7$ to 4.1$)$ & $2.7(2.4$ to 3.2$)$ \\
\hline 200 & 2 & $106 / 191(55)$ & $32 / 181(18)$ & $3.1(2.2$ to 4.3$)$ & $2.6(2.1$ to 3.5$)$ \\
\hline Dose optimised & 3 & $227 / 379(60)$ & $70 / 376(19)$ & $3.2(2.6$ to 4.0$)$ & $2.4(2.1$ to 2.9$)$ \\
\hline
\end{tabular}

The results for at least $40 \%$ success are shown in Table 2 and Figure 2. All doses were significantly better than placebo. In three studies $60 \%$ of men had this outcome with dose optimisation compared with $19 \%$ with placebo; the number needed to treat was 2.4 (95\% CI 2.1 to 2.9 ). Dose-optimisation produced a significantly lower (better) NNT than a $25 \mathrm{mg}$ fixed dose.

More men responded positively to the global question about improved erections with sildenafil than with placebo (Table 3, Figure 3). All doses were significantly better than placebo. In five studies $79 \%$ of men responded positively with dose optimisation compared with $21 \%$ with placebo; the number needed to treat was 1.7 (1.6 to 1.9 ). Dose-optimisation produced a significantly lower (better) NNT than $25 \mathrm{mg}$ and $50 \mathrm{mg}$ fixed doses.

Responses on IIEF questions 3 and 4 were not given as proportions, but as means. Pooling of mean data was not attempted.

\section{Erections}

The weighted mean number of erections per week and successful erections in which intercourse took place with different doses of sildenafil and with placebo are shown in Figure 4. With placebo erections with successful intercourse occurred on average less often than once every five weeks. With dose optimised sildenafil they occurred more often than once a week. Dose optimisation produced more successful erections, and more erections in total, than did $50 \mathrm{mg}$ or $100 \mathrm{mg}$ fixed dose sildenafil.

\section{Adverse events}

Treatment related adverse events are shown in Table 4. They occurred more frequently with sildenafil than with placebo for all doses. Dose optimisation produced 30\% of patients with adverse events compared with $11 \%$ with placebo; the number needed to harm was 5.4 (4.3 to 7.3). This was significantly greater (better) than $100 \mathrm{mg}$ and $200 \mathrm{mg}$ fixed doses.

Serious adverse events were no more frequent with sildenafil than placebo at any dose (Additional File 4). Adverse 
Table 3: Positive response to global question about improved erections

\begin{tabular}{|c|c|c|c|c|c|}
\hline \multirow[b]{2}{*}{ Dosing (mg) } & \multirow[b]{2}{*}{ Number of trials } & \multicolumn{3}{|c|}{ Number (\%) with outcome } & \multirow[b]{2}{*}{ NNT $(95 \%$ CI } \\
\hline & & Sildenafil & Placebo & $\begin{array}{l}\text { Relative benefit } \\
(95 \% \mathrm{Cl})\end{array}$ & \\
\hline 25 & 3 & $192 / 312(62)$ & $114 / 426(27)$ & 2.3 (1.9 to 2.8$)$ & $2.8(2.4$ to 3.5$)$ \\
\hline 50 & 5 & $378 / 5 \mid I(74)$ & $153 / 607(25)$ & $3.0(2.6$ to 3.5$)$ & 2.1 (1.9 to 2.3$)$ \\
\hline 100 & 5 & $4 \mid 5 / 506$ (82) & $153 / 607(25)$ & 3.3 (2.9 to 3.8$)$ & 1.8 (1.6 to 1.9$)$ \\
\hline 200 & 2 & $152 / 19 \mid(80)$ & $39 / 181(22)$ & 3.7 (2.8 to 5.0$)$ & 1.7 (1.5 to 2.0$)$ \\
\hline Dose optimised & 5 & $4|I / 5| 7(79)$ & $1 \mathrm{I} / / 524(21)$ & 3.8 (3.2 to 4.5$)$ & 1.7 (I.6 to I.9) \\
\hline
\end{tabular}

\section{Men with at least $40 \%$ success Percent with sildenafil}

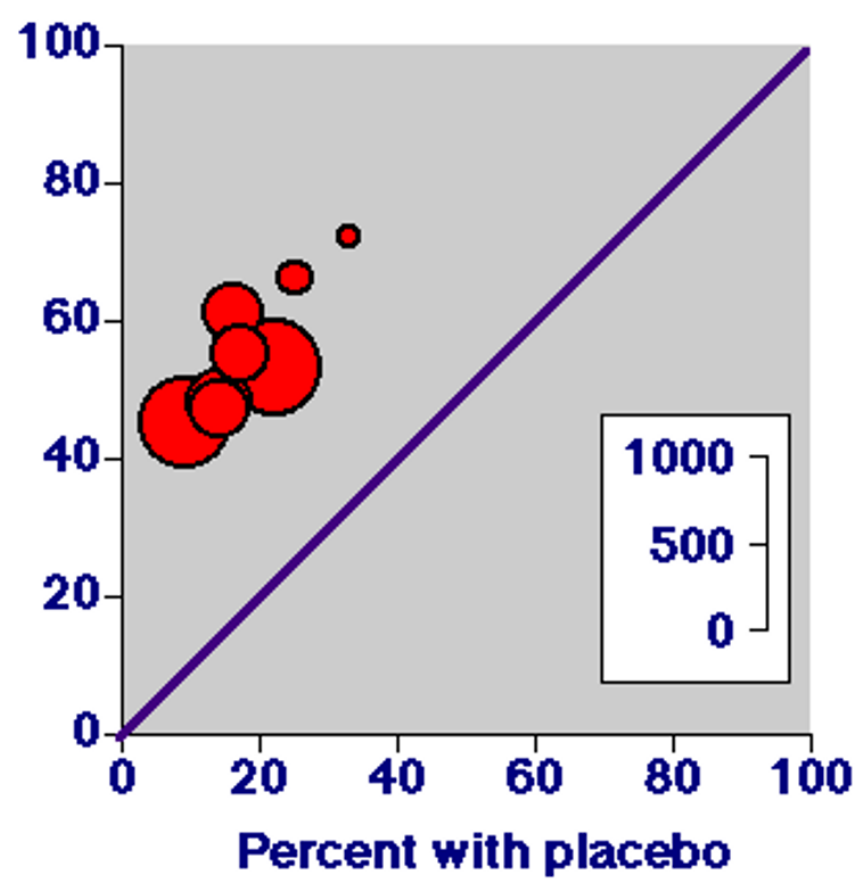

Figure 2

Each symbol represents the percentage of men with at least $40 \%$ success with viagra or placebo. Size of the symbol is proportional to the size of the study

events described as severe occurred more frequently than placebo with $100 \mathrm{mg}$ and $200 \mathrm{mg}$ fixed doses, but not with dose optimisation or $25 \mathrm{mg}$ or $50 \mathrm{mg}$ fixed doses (Additional File 5).

\section{Men with improved erections} Percent with sildenafil

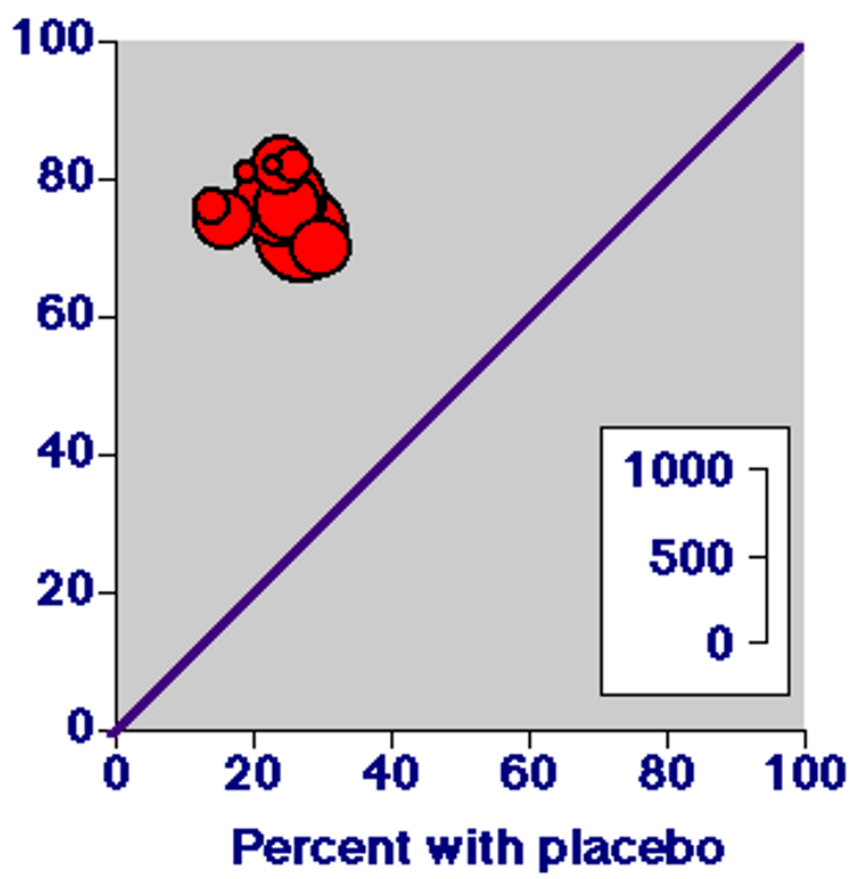

Figure 3

Each symbol represents the percentage of men with improved erections with viagra or placebo using the global score. Size of the symbol is proportional to the size of the study

Consistent information was available from clinical trial reports for three specific adverse events - dyspepsia, headache and vasodilation. The incidence of these all increased with dose (Table 5), resulting in lower (worse) values for NNH. For dyspepsia, dose optimisation produced signifi- 
Table 4: Treatment related adverse events

Number (\%) with outcome

Dosing (mg) Number of trials

Sildenafil

Placebo

Relative risk $(95 \%$

CI)

NNH $(95 \% \mathrm{Cl})$

\begin{tabular}{cccccc}
\hline 25 & 3 & $71 / 312(23)$ & $33 / 426(8)$ & $2.8(1.9$ to 4.2$)$ & $6.7(4.9$ to 10$)$ \\
50 & 5 & $190 / 508(37)$ & $59 / 607(10)$ & $3.7(2.8$ to 4.8$)$ & $3.6(3.1$ to 4.4$)$ \\
100 & 5 & $260 / 506(51)$ & $59 / 607(10)$ & $5.0(3.9$ to 6.5$)$ & $2.4(2.2$ to 2.7$)$ \\
200 & 2 & $137 / 191(72)$ & $26 / 181(14)$ & $5.0(3.5$ to 7.2$)$ & $1.7(1.5$ to 2.0$)$ \\
Dose optimised & 5 & $155 / 517(30)$ & $60 / 524(11)$ & $2.6(2.0$ to 3.4$)$ & $5.4(4.3$ to 7.3$)$ \\
\hline
\end{tabular}

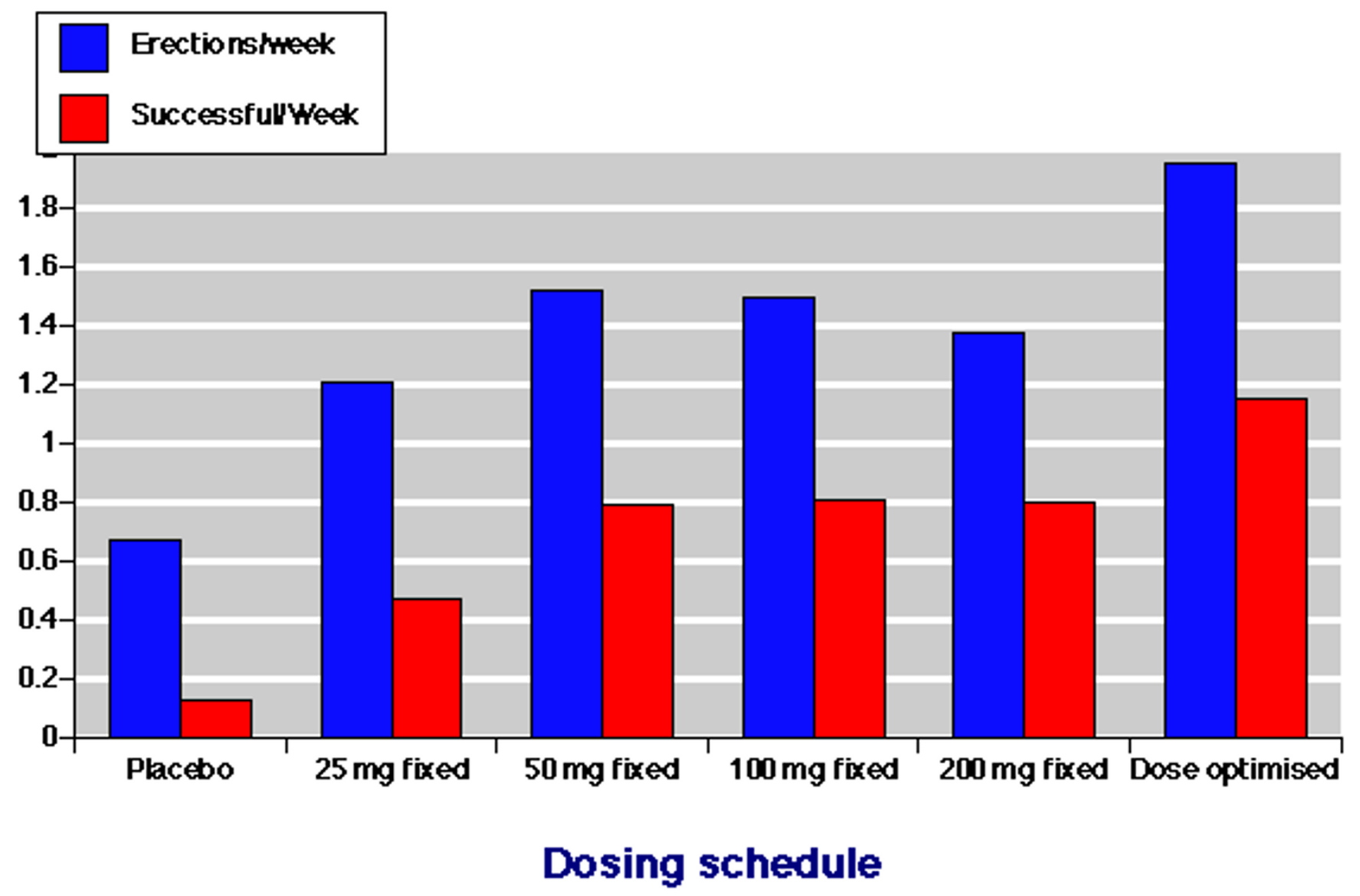

Figure 4

Mean number of erections a week (blue), and erections resulting in successful intercourse (red) with placebo and different doses and dosing schedules of sildenafil

cantly higher (better) NNH values than did $50 \mathrm{mg}, 100$ mg or $200 \mathrm{mg}$. For headache, dose optimisation produced significantly higher NNH values than $100 \mathrm{mg}$ and 200 mg. For vasodilation, dose optimisation produced similar $\mathrm{NNH}$ values to all fixed doses.

\section{Discontinuations}

All cause discontinuations are shown in Table 6. All cause discontinuations were significantly lower with sildenafil at $50 \mathrm{mg}$ and $100 \mathrm{mg}$ fixed doses and with dose optimisation. 
Table 5: Specific adverse events (treatment related) in comparisons with placebo

\begin{tabular}{|c|c|c|c|c|c|c|}
\hline \multirow[b]{2}{*}{ Dosing (mg) } & \multirow[b]{2}{*}{$\begin{array}{c}\text { Number of } \\
\text { trials }\end{array}$} & \multirow[b]{2}{*}{ Adverse event } & \multicolumn{3}{|c|}{ Number (\%) with outcome } & \multirow[b]{2}{*}{ NNH $(95 \% \mathrm{Cl})$} \\
\hline & & & Sildenafil & Placebo & Relative risk $(95 \% \mathrm{Cl})$ & \\
\hline \multirow[t]{3}{*}{25} & 3 & Dyspepsia & $4 / 3 \mid 2(1.2)$ & $1 / 426(0.2)$ & \multicolumn{2}{|c|}{$4.4(0.6$ to 34$)$} \\
\hline & & Headache & $31 / 312(10)$ & $14 / 426(3.2)$ & $3.1(1.6$ to 6.1$)$ & $15(9.6$ to 34$)$ \\
\hline & & Vasodilation & $30 / 312(9.6)$ & $4 / 426(1.0)$ & II (3.8 to 29$)$ & $12(8.3$ to 19$)$ \\
\hline \multirow[t]{3}{*}{50} & 5 & Dyspepsia & $24 / 511(4.7)$ & $4 / 607(0.7)$ & $6.4(2.4$ to 17$)$ & 24 (17 to 47$)$ \\
\hline & & Headache & $77 / 511(15)$ & $21 / 607(0.3)$ & 4.5 (2.8 to 7.3$)$ & $8.6(6.6$ to 12$)$ \\
\hline & & Vasodilation & $94 / 511(18)$ & $11 / 607(1.8)$ & $9.7(5.4$ to 18$)$ & $6.0(5.0$ to 7.7$)$ \\
\hline \multirow[t]{3}{*}{100} & 5 & Dyspepsia & $60 / 506(12)$ & $4 / 607(0.7)$ & $15(5.8$ to 40$)$ & $8.9(7.1$ to 12$)$ \\
\hline & & Headache & $115 / 506(23)$ & $21 / 607(0.3)$ & $6.8(4.3$ to 11$)$ & $5.2(4.3$ to 6.5$)$ \\
\hline & & Vasodilation & $90 / 506(17)$ & $1 \mathrm{l} / 607(1.8)$ & $9.2(5.0$ to 17$)$ & $6.3(5.1$ to 8.0$)$ \\
\hline \multirow[t]{3}{*}{200} & 2 & Dyspepsia & 35/191 (18) & $3 / 181$ (1.7) & II (3.5 to 35$)$ & 6.0 (4.5 to 9.2$)$ \\
\hline & & Headache & 62/191 (32) & $7 / 181$ (3.9) & $8.4(4.0$ to 18$)$ & 3.5 (2.8 to 4.7$)$ \\
\hline & & Vasodilation & 43/191 (22) & $7 / 181$ (3.9) & $5.9(2.7$ to 13$)$ & $5.4(4.0$ to 8.3$)$ \\
\hline \multirow[t]{3}{*}{ Dose optimised } & 5 & Dyspepsia & $24 / 517(4.6)$ & $7 / 524$ (I.3) & 3.4 (1.5 to 7.9$)$ & 31 (19 to 82) \\
\hline & & Headache & $63 / 517(12)$ & $10 / 524(1.9)$ & $6.3(3.2$ to 12$)$ & $9.8(7.5$ to 14$)$ \\
\hline & & Vasodilation & $65 / 517(13)$ & $4 / 524(0.8)$ & 16 (6.0 to 44$)$ & 8.5 (6.7 to II) \\
\hline
\end{tabular}

Table 6: All cause discontinuations

\begin{tabular}{|c|c|c|c|c|c|}
\hline \multirow[b]{2}{*}{ Dosing (mg) } & \multirow[b]{2}{*}{ Number of trials } & \multicolumn{3}{|c|}{ Number (\%) with outcome } & \multirow[b]{2}{*}{ NNH $(95 \% \mathrm{Cl})$} \\
\hline & & Sildenafil & Placebo & $\begin{array}{l}\text { Relative risk ( } 95 \% \\
\text { CI) }\end{array}$ & \\
\hline 25 & 3 & $32 / 312(10)$ & $63 / 426(15)$ & $0.75(0.50$ to 1.11$)$ & \\
\hline 50 & 5 & $36 / 508(7)$ & $86 / 607(14)$ & $0.52(0.36$ to 0.76$)$ & $-14(-9$ to -28$)$ \\
\hline 100 & 5 & $47 / 506(9)$ & $86 / 607(14)$ & $0.67(0.47$ to 0.95$)$ & $-20(-12$ to -89$)$ \\
\hline 200 & 2 & $18 / 191(9)$ & $23 / 181(13)$ & $0.76(0.43$ to 1.35$)$ & \\
\hline Dose optimised & 5 & $52 / 517(10)$ & $104 / 524(20)$ & $0.50(0.37$ to 0.67$)$ & $-10(-7$ to -18$)$ \\
\hline
\end{tabular}

Discontinuations because of lack of efficacy were significantly lower with sildenafil at $50 \mathrm{mg}$ and $100 \mathrm{mg}$ fixed doses and with dose optimisation (Additional File 6).

Discontinuations due to adverse effects were not different between sildenafil at any dose and placebo (Additional File 7).

\section{Discussion}

This review demonstrated that considerable amounts of useful information are available in clinical trial reports submitted for marketing authorisation (licensing). That information adequately describes research methods used, though could be improved, perhaps using the updated CONSORT criteria [17]. If these guidelines are becoming necessary for publication of randomised trials in our major medical journals, then they should be minimum criteria for clinical trials reports required by licensing authorities. We did not check the reports against each CONSORT criterion because the reports were from 1997 soon after the publication of the original CONSORT statement [17].

Despite scores of 3 or 4 out of five on a commonly-used quality score, and acknowledging that scores like this are not associated with bias $[18,19]$, the areas where the clin- 


\section{Percent}

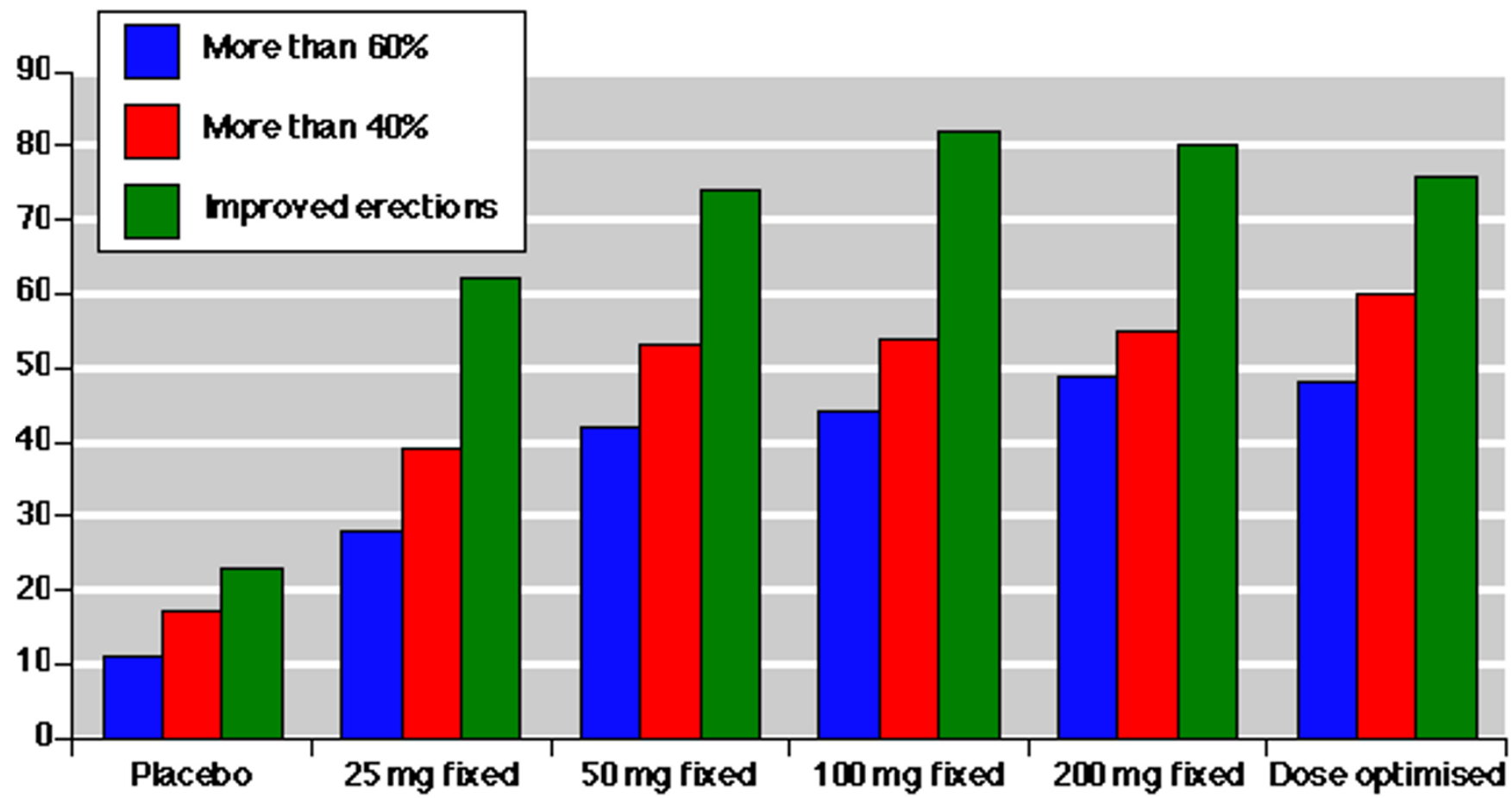

\section{Dosing schedule}

\section{Figure 5}

Mean percentage of men achieving the outcomes of more than $60 \%$ success (blue) more than $40 \%$ success (red) and improved erections on the global question (green) with placebo and different doses and dosing schedules of sildenafil

ical trials reports were weak were important ones. Only two reports stated how the randomisation sequence was generated. No report adequately described allocation concealment, though several mentioned sealed envelopes. No report described the implementation of the allocation sequence. Only two reports described how double blinding was achieved.

In other areas, reporting was good. Participants, and inclusion and exclusion criteria were explicit, as was a description of the intervention. Patient flow (though without diagrams) was thoroughly described, together with reasons for withdrawal. Baseline information on participants, numbers analysed and methods used were all well described, both for efficacy and adverse events. One criticism, outside CONSORT, was the use of mean scores for results of IIEF questions. Mean scores are of little value, especially when there may not be a normal distribution when they can be misleading [10]. Better would be the number or proportion of men achieving good or excellent outcomes.
Clinical trial reports were a good source of information, and with minor changes would become an excellent source of information for meta-analysis. For sildenafil in erectile dysfunction these reports allowed interesting conclusions to be drawn from a homogeneous population of men with similar aetiologies, but excluding those with erectile dysfunction following spinal cord trauma, with diabetes, or following treatment for prostate cancer. Although two small studies on spinal cord trauma and one on diabetes were available in the full review, much more information on men with erectile dysfunction of particular aetiology has become available since 1997 [19], [19], [20], [21], [22], [23].

Efficacy was available in a number of formats in addition to mean responses to IIEF scores 3 and 4 . The number of men in whom sildenafil was successful (erections hard enough for penetration, and resulting in intercourse) more than $60 \%$ of the time, and more than $40 \%$ of the time was available, and chosen by us for evaluation. Cut points every $20 \%$ from $0 \%$ to $100 \%$ were also available. 


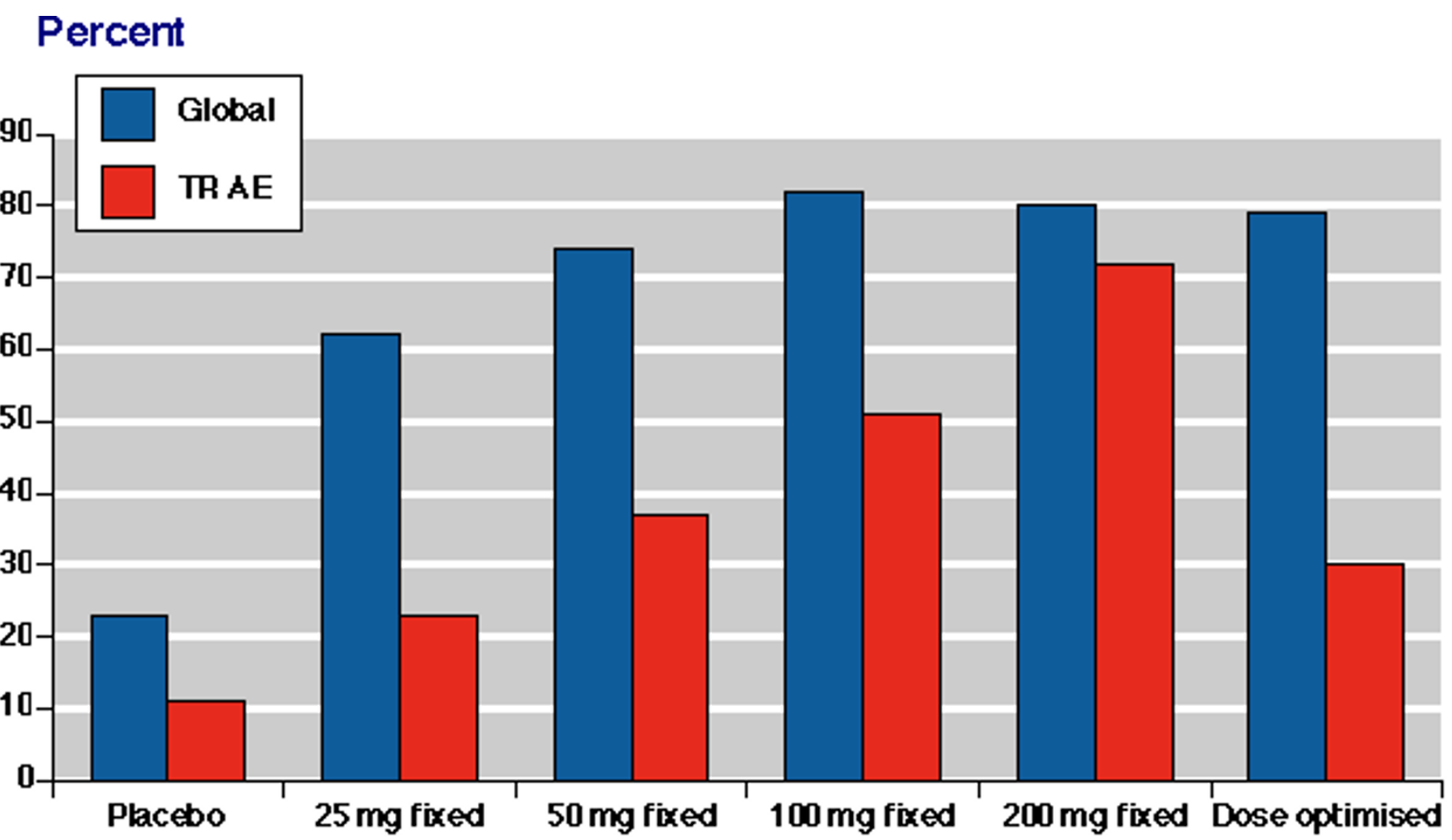

\section{Dosing schedule}

\section{Figure 6}

Mean percentage of men with improved erections on a global scale (blue), and reporting treatment related adverse effects (red) with placebo and different doses and dosing schedules of sildenafil

The number of men responding positively to the global question on improved erections was also available. Clearly there is a gradation here from outcomes that are less easy to achieve to those that are easier to fulfil. A greater proportion of men achieved the easier than harder outcome for all doses (Figure 5). Numbers needed to treat and the proportion of patients achieving the outcome could easily be calculated.

Adverse events were also well described, and presented in a number of formats, from the number of men with any treatment related adverse event, through the number with severe or serious adverse events, particular adverse events, and discontinuations. From these it was possible to calculate numbers needed to harm and the proportion of patients for each outcome.

The ability to perform these calculations with information pooled from 10 studies was informative. Firstly, it supported the optimised dosing regimen for sildenafil. Optimised dosing produced efficacy equivalent to the highest fixed dose, and harm equivalent to the lowest fixed dose. Figure 6 shows the effects on the two broadest efficacy and harm outcomes, global response about improved erections and treatment related adverse effects. Figure 7 shows the NNTs and NNHs for three efficacy outcomes, three harm outcomes and three discontinuation outcomes. Optimised dosing was better than fixed dosing.

It is also germane to enquire whether results obtained from clinical trial reports of the earliest studies are borne out in later reviews. A review of 20 trials comparing sildenafil with placebo with about 4,000 men included both published and unpublished information, and supplemented by the manufacturer where appropriate, arrived at broadly similar results [24]. Only seven of the references to trials in that review were dated 1997 or before (mostly as abstracts), and would have been available at the time of marketing approval. Though combining all doses of sildenafil from $5 \mathrm{mg}$ to $200 \mathrm{mg}$ and dose escalation together in a comparison with placebo, the result for global efficacy 


\begin{tabular}{|c|ccc|cccc|}
\cline { 2 - 7 } & \multicolumn{3}{c|}{ Efficacy } & \multicolumn{3}{c|}{ Harm } \\
\cline { 2 - 8 } Dosing (mg) & $60 \%$ & $40 \%$ & Global & TR AE & Disc & Disc IE DiscAE Serious Serere \\
\hline 25 & 5.5 & 4.5 & 2.8 & 6.7 & & \\
50 & 3.1 & 2.8 & 2.1 & 3.6 & -14 & -28 \\
100 & 3.0 & 2.7 & 1.8 & 2.4 & -20 & -27 & 25 \\
200 & 2.6 & 2.6 & 1.7 & 1.7 & & & 15 \\
\hline Dose optimised & 2.7 & 2.4 & 1.7 & 5.4 & -10 & -12 & 45 \\
\hline All 25-100 mg & 3.2 & 2.9 & 1.9 & 3.8 & -12 & -18 & \\
\hline
\end{tabular}

Note: dose optimisation in the range of $25-100 \mathrm{mg}$ as needed produces efficacy equivalent to $100 \mathrm{or} 200 \mathrm{mg}$ fixed dose, but with fewer treabment-related adverse events and discontinuations (total and inefficacy). Discontinuations because of adverse events, or severe or serious adverse effects, were no more frequent with dose optimisation than with placebo.

indicated no significant difference from placebo

\section{Figure 7}

Number needed to treat for different efficacy outcomes (more than $60 \%$ success, more than $40 \%$ success and improvement on global question) and number needed to harm for different adverse event outcomes (treatment related adverse events, all cause discontinuations, discontinuations due to inefficacy and adverse events and serious and severe adverse events). For NNT low numbers are better and for NNH high or negative numbers are better. TR AE - treatment related adverse event, Disc - discontinuation

yielded an NNT of 2, the same as is found in this review for all doses higher than $25 \mathrm{mg}$ (Table 3 ).

This investigation of the evidential properties of clinical trial reports of sildenafil for treatment of erectile dysfunction indicates that, in this instance, reports could have been used for systematic review at the time of product launch. With little additional effort the clinical trial reports could have fulfilled CONSORT guidelines for the reporting of randomised controlled trials. Making clinical trial reports publicly available at the time of product launch, perhaps through the Internet, would make their introduction evidence-based, as well as allowing healthcare services to plan ahead more effectively. This would benefit commercial organisations by maximising the uptake of effective new technology, and may accelerate discontinuation of less effective, or less safe, older technology.

\section{Conclusions}

Clinical trial reports presented for marketing approval did provide the basis for a systematic review at the time of launch for sildenafil for the treatment of male erectile dys- function. To our knowledge these documents were not publicly available at the time. Were clinical trials reports used for marketing approval publicly available, then review and meta-analysis would allow an early appreciation of benefits or pitfalls $\S$ for patients and healthcare systems.

\section{Competing interests}

RAM has received lecture fees on one occasion related to erectile dysfunction. All authors have worked with commercial, government and charities in relation to healthcare, but not in regard to erectile dysfunction.

\section{Authors' contributions}

RAM read each report, abstracted information and analysis, and performed quality scoring. JE read each report, checked abstracted information and analysis, and performed quality score. HJM checked quality scores. All authors contributed equally to the preparation and writing of the manuscript. 


\section{Additional material}

\section{Additional file 1}

Excluded studies - a list of the studies excluded from the review.

Click here for file

[http://www.biomedcentral.com/content/supplementary/1471-

2490-2-6-S1.pdf]

\section{Additional file 2}

Included studies - a list of the studies included with details of patient condition, design, dosing, controls, blinding, entry criteria and quality score. Click here for file

[http://www.biomedcentral.com/content/supplementary/1471-

2490-2-6-S2.pdf

\section{Additional file 3}

Details of the results for included studies for each treatment group in each study. Efficacy variables (erections and sexual intercourse) and adverse events (including discontinuations) are listed.

Click here for file

[http://www.biomedcentral.com/content/supplementary/14712490-2-6-S3.pdf]

\section{Additional file 4}

Details of serious adverse results by dose.

Click here for file

[http://www.biomedcentral.com/content/supplementary/1471-

2490-2-6-S4.pdf]

\section{Additional file 5}

Details of severe adverse results by dose.

Click here for file

[http://www.biomedcentral.com/content/supplementary/1471-

2490-2-6-S5.pdf]

\section{Additional file 6}

Details of inefficacy discontinuations by dose.

Click here for file

[http://www.biomedcentral.com/content/supplementary/1471-

2490-2-6-S6.pdf]

\section{Additional file 7}

Details of adverse event discontinuations by dose.

Click here for file

[http://www.biomedcentral.com/content/supplementary/14712490-2-6-S7.pdf

\section{Acknowledgements}

The work was supported by an unrestricted educational grant from Pfizer Ltd, and by Pain Research Funds. The terms of the Pfizer grant included an absolute right of the authors to publish the results of their work. Pfizer did see the manuscript before submission.

\section{References}

I. Moore RA, McQuay HJ: Single-patient data meta-analysis of $\mathbf{3 4 5 3}$ postoperative patients: Oral tramadol versus placebo, codeine and combination analgesics. Pain 1997, 69:287-294

2. Sunshine A, Olson NZ, Zighelboim I, et al: Analgesic oral efficacy of tramadol hydrochloride in postoperative pain. Clin Pharmacol Ther 1992, 51:740-6
3. Stubhaug A, Grimstad J, Breivik H: Lack of analgesic effect of $\mathbf{5 0}$ and $100 \mathrm{mg}$ oral tramadol after orthopaedic surgery: a randomized, double-blind, placebo and standard active drug comparison Pain 1995, 62:111-8

4. Edwards J, Moore A: Implanon. A review of clinical studies. The British Journal of Family Planning 1999, 24:3-16

5. Langman MJ, Jensen DM, Watson DJ, et al: Adverse upper gastrointestinal effects of rofecoxib compared with NSAIDs. JAMA 1999, 282:1929-1933

6. Goldstein JL, Silverstein FE, Agrawal NM, et al: Reduced risk of upper gastrointestinal ulcer complications with celecoxib, a novel COX-2 inhibitor. Am J Gastroenterol 2000, 95: I 68I - I690

7. Moher D, Cook DJ, Eastwood Sea: Improving the quality of reports of meta-analyses of randomised controlled: the QUOROM statement. The Lancet 1999, 354: I 896-1900

8. Jadad AR, Moore RA, Carroll D, et al: Assessing the quality of reports of randomized clinical trials: is blinding necessary? Controlled Clinical Trials 1996, I 7: I-12

9. Rosen RC, Riley A, Wagner G, et al: The international index of erectile function (IIEF): a multidimensional scale for assessment of erectile disfunction. Urology 1997, 49:822-830

10. McQuay H, Carroll D, Moore A: Variation in the placebo effect in randomised controlled trials of analgesics: All is as blind as it seems. Pain 1996, 64:331-335

II. Morris J, Gardner M: Statistics in Medicine : Calculating, confidence intervals for relative risks (odds ratios) and standardised ratios and rates. British Medical Journal 1988, 296: I 313

12. Cook RJ, Sackett DL: The number needed to treat: a clinically useful measure of treatment effect. British Medical Journal I995, 3 I 0:452-4

13. Gavaghan DJ, Moore RA, McQuay HJ: An evaluation of homogeneity tests in meta-analyses in pain using simulations of individual patient data. Pain 2000, 85:4I5-424

14. L'Abbé KA, Detsky AS, O'Rourke K: Meta-analysis in clinical research. Ann Intern Med 1 987, I 07:224-33

15. Tang J-L, Liu JLY: Misleading funnel plot for detection of bias in meta-analysis. Journal of Clinical Epidemiology 2000, 53:477-484

16. Tramèr MR, Reynolds DJM, Moore RA, McQuay HJ: Impact of covert duplicate publication on meta-analysis: a case study. British Medical Journal 1997, 3 I 5:635-9

17. Begg C, Cho M, Eastwood S, et al: Improving the quality of reporting of randomized controlled trials. The CONSORT statement. JAMA 1996, 276:637-9

18. Khan KS, Daya S, Collins JA, Walter SD: Empirical evidence of bias in infertility research: overestimation of treatment effect in crossover trials using pregnancy as the outcome measure. Fertility and Sterility 1996, 65:939-945

19. Giuliano F, Hultling C, El Masry WS, et al: Randomized trial of sildenafil for the treatment of erectile dysfunction in spinal cord injury. Sildenafil Study Group. Ann Neurol 1999, 46:| 5-2।

20. Maytom MG, Derry FA, Dinsmore WW, et al: A two-part pilot study of sildenafil (VIAGRA) in men with erectile dysfunction caused by spinal cord injury. Spinal Cord 1999, 37: I I 0-1 I6

21. Derry F, Glass C, Dinsmore W, et al: Sildenafil (Viagra): An oral treatment for erectile dysfunction caused by traumatic cord injury-a 28 day, double-blind, placebo controlled, parallelgroup, dose response [Abstract]. Journal of the Neurological Sciences 1997, S270

22. Rendell MC, Rafjer J, Wicker PA, et al: Sildenafil for treatment of erectile dysfunction in men with diabetes. A randomized controlled trial. JAMA 1999, 28 I:421-426

23. Price DE, Gingell JC, Gepi Attee S, et al: Sildenafil: study of a novel oral treatment for erectile dysfunction in diabetic men. Diabet Med 1998, I 5:82 I-5

24. Burls A, Gold L, Rutks IR, Clark W: Systematic review of randomized controlled trials of sildenafil (Viagra ${ }^{\circledR}$ ) in the treatment of male erectile dysfunction. Br J Gen Pract 200 I, 5 I : I0041012

\section{Pre-publication history}

The pre-publication history for this paper can be accessed here:

http://www.biomedcentral.com/1471-2490/2/6/prepub 